Simultaneous identification and quantification of new psychoactive substances in blood by GC-APCI-QTOFMS coupled to nitrogen chemiluminescence detection without authentic reference standards

\title{
Ojanpera, Ilkka
}

\section{6-05}

Ojanpera , I , Mesihää , S , Rasanen , I , Pelander , A \& Ketola , R A 2016 , ' Simultaneous identification and quantification of new psychoactive substances in blood by GC-APCI-QTOFMS coupled to nitrogen chemiluminescence detection without authentic reference standards ', Analytical and Bioanalytical Chemistry, vol. 408 , no. 13 , pp. 3395-3400 . https://doi.org/10.1007/s00216-016-9461-8

http://hdl.handle.net/10138/231527

https://doi.org/10.1007/s00216-016-9461-8

publishedVersion

Downloaded from Helda, University of Helsinki institutional repository.

This is an electronic reprint of the original article.

This reprint may differ from the original in pagination and typographic detail.

Please cite the original version. 


\title{
Simultaneous identification and quantification of new psychoactive substances in blood by GC-APCI-QTOFMS coupled to nitrogen chemiluminescence detection without authentic reference standards
}

\author{
Ilkka Ojanperä ${ }^{1,2} \cdot$ Samuel Mesihää ${ }^{1} \cdot$ Ilpo Rasanen $^{2} \cdot$ Anna Pelander $^{2}$ • \\ Raimo A. Ketola ${ }^{2}$
}

Received: 10 January 2016 /Revised: 24 February 2016/Accepted: 1 March 2016/Published online: 11 March 2016

(C) Springer-Verlag Berlin Heidelberg 2016

\begin{abstract}
A novel platform is introduced for simultaneous identification and quantification of new psychoactive substances (NPS) in blood matrix, without the necessity of using authentic reference standards. The instrumentation consisted of gas chromatography (GC) coupled to nitrogen chemiluminescence detection (NCD) and atmospheric pressure chemical ionization quadrupole time-of-flight mass spectrometry (APCI-QTOFMS). In this concept, the GC flow is divided in appropriate proportions between NCD for single-calibrant quantification, utilizing the detector's equimolar response to nitrogen, and QTOFMS for accurate mass-based identification. The principle was proven by analyzing five NPS, bupropion, desoxypipradrol (2-DPMP), mephedrone, methylone, and naphyrone, in sheep blood. The samples were spiked with the analytes post-extraction to avoid recovery considerations at this point. All the NPS studies produced a protonated molecule in APCI resulting in predictable fragmentation with high mass accuracy. The $N$-equimolarity of quantification by NCD was investigated by using external calibration with the secondary standard caffeine at five concentration levels between 0.17 and $1.7 \mathrm{mg} / \mathrm{L}$ in blood matrix as five replicates. The equimolarity was on average $98.7 \%$, and the range of individual equimolarity determinations was $76.7-130.1 \%$. The current analysis platform affords a promising approach to instant simultaneous qualitative and
\end{abstract}

Ilkka Ojanperä

ilkka.ojanpera@helsinki.fi

1 Department of Forensic Medicine, University of Helsinki, PO Box 40, 00014 Helsinki, Finland

2 Forensic Toxicology Unit, National Institute for Health and Welfare, PO Box 30, 00271 Helsinki, Finland quantitative analysis of drugs in the absence of authentic reference standards, not only in forensic and clinical toxicology but also in other bioanalytical applications.

Keywords New psychoactive substances $\cdot$ Nitrogen chemiluminescence detection - Gas chromatography . Accurate mass - Atmospheric pressure chemical ionization . Time-of-flight mass spectrometry

\section{Introduction}

Identification and quantification of drugs and metabolites without possessing the authentic reference standards is a challenge in many areas of bioanalysis. In forensic toxicology, the recent emergence of new psychoactive substances (NPS), with more than one hundred new substances entering the illicit market in Europe in 2014, makes it difficult for the laboratories to equip themselves with appropriate reference standards even for the most prevalent new drugs and their metabolites.

High-resolution mass spectrometric techniques (HRMS) have found extensive use in clinical and forensic toxicology and doping control [1], and efficient data-independent acquisition methods are now utilized for substance identification together with comprehensive spectral libraries [2]. However, while there is forceful progress in the identification of drugs by HRMS, quantification without reference standards remains mostly uncompleted using the conventional analytical armory. Rather complicated techniques beyond the scope of most forensic laboratories have been used for quantification, such as accelerator MS, or comparison of response factors established between MS and radioactivity detection or NMR [3].

Liquid chromatography (LC) coupled to nitrogen chemiluminescence detection (NCD) can be used with a single 
external nitrogenous calibrant to quantify nitrogen-containing compounds of known molecular formula, based on the detector's equimolar response to nitrogen. We have previously applied LC-NCD to the quantification of the active components of confiscated street drugs without authentic reference standards [4]. As approximately $90 \%$ of drugs contain nitrogen, the $\mathrm{N}$-equimolar response of this detector enabled facile quantification of both traditional illicit drugs and NPS using a single secondary standard, caffeine, for calibration [5].

However, the LC-NCD approach is not equally feasible in bioanalytical applications due to the limited sensitivity and fairly slow data acquisition capacity of the detector, necessitating high sample volumes and broad LC peak widths, respectively $[6,7]$. In a bioanalytical context, the NCD detector's equimolar response to nitrogen is likely to be better exploited by using an instrument version designed for gas chromatography (GC), possessing a higher sensitivity and acquisition frequency than what could be obtained by the LC version. There are no previous applications of GC-NCD to drug bioanalysis taking advance of the $N$-equimolarity principle.

Our objective was to develop a new integrated platform for simultaneous identification and quantification of NPS in biological material, without the necessity of using authentic reference standards. The concept takes advantage of current atmospheric pressure chemical ionization GC interfacing to quadrupole time-of-flight MS (GC-APCI-QTOFMS). In our approach, the GC flow is divided in appropriate proportions between TOFMS and NCD, for accurate mass-based identification and for single-calibrant quantification, respectively. Recovery issues are not taken into consideration at this point but the experiments are carried out using sheep blood samples spiked post-extraction to produce a realistic matrix background.

\section{Materials and methods}

Reference standards Bupropion was as a gift from GlaxoSmithKline (Brentford, Middlesex, UK). Mephedrone was purchased from Toronto Research Chemicals (North York, ON, Canada), methylone and naphyrone from LGC GmbH (Luckenwalde, Germany), and desoxypipradrol (2DPMP) from SynChem (Elk Grove Village, IL). The internal standard dibenzepine-D3 was purchased from Toronto Research Chemicals, and the external secondary standard caffeine from Sigma-Aldrich Finland (Helsinki, Finland).

Sample preparation Each reference standard was weighed and dissolved in methanol to obtain stock solutions of $1 \mathrm{mg} /$ $\mathrm{mL}$. These solutions were mixed and diluted with butyl acetate to obtain $1,2,3,5$, and $10 \mu \mathrm{g} / \mathrm{mL}$ reference standard working mixtures in butyl acetate.
Sheep whole blood containing $1 \% \mathrm{NaF}$ was used for the experiments. The blood sample $(1.0 \mathrm{~g})$ was transferred into a 6-mL centrifuge tube, $300 \mu \mathrm{L}$ of $1 \mathrm{M}$ Tris buffer ( $\mathrm{pH} 11)$ was mixed with the sample, and the mixture was extracted in a vortex mixer with $300 \mu \mathrm{L}$ of butyl acetate for $2 \mathrm{~min}$. After centrifugation, an aliquot $(150 \mu \mathrm{L})$ of the organic phase was transferred into a conical autosampler vial. Thereafter, the internal standard $(20 \mu \mathrm{L}, 25 \mu \mathrm{g}$ dibenzepin-D3 in butyl acetate) and $35 \mu \mathrm{L}$ of the reference standard mixtures were added.

Analytical platform A 7890B Series GC System equipped with a 7693 Automatic Liquid Sampler and a split/splitless injector was coupled through a G3180B Two-Way Splitter with Makeup Gas to an APCI 6540 UHD Accurate-Mass QTOF mass analyzer and a 255 Nitrogen Chemiluminescence Detector (all Agilent Technologies, Santa Clara, CA).

GC analysis The injector liner was a Single taper Ultra Inert liner with glass wool (Agilent 5190-2293). The analytical column was a DB-5MS $(30 \mathrm{~m} \times 0.25 \mathrm{~mm}$ id with $0.1 \mu \mathrm{m}$ film $)$ capillary column (Agilent Technologies). After the analytical column, the GC flow was divided between the NCD and the APCI ion source through the two-way splitter, using $0.55 \mathrm{~m} \times 0.18 \mathrm{~mm}$ and $2 \mathrm{~m} \times 0.18 \mathrm{~mm}$ uncoated deactivated fused-silica post-columns to obtain a 10:1 flow ratio, respectively. The splitter pressure was $15.8 \mathrm{psi}$ and the flow ratio was calculated using the Effluent Splitter Calculator (with Makeup) (Agilent Technologies). The GC was operated in the pulsed splitless injection mode with an equilibration time of $0.5 \mathrm{~min}$ and $50 \mathrm{~mL} / \mathrm{min}$ purge flow to split vent at $0.75 \mathrm{~min}$. A pulse pressure of $50 \mathrm{psi}$ for $0.75 \mathrm{~min}$ was applied prior to using an initial head pressure of 24.9 psi. The injector port temperature was $250{ }^{\circ} \mathrm{C}$ and the transfer line temperature $320^{\circ} \mathrm{C}$. The injection volume was $1.5 \mu \mathrm{L}$.

The oven temperature was initially held at $100{ }^{\circ} \mathrm{C}$ for $0.5 \mathrm{~min}$ and then increased by $30^{\circ} \mathrm{C}$ per min to $320^{\circ} \mathrm{C}$, which was held for $6 \mathrm{~min}$. Helium was used as carrier gas at $1 \mathrm{~mL} /$ min in the constant flow mode.

APCI-QTOFMS analysis The QTOFMS was operated in the APCI positive ionization mode, drying gas (nitrogen) flow at $5.0 \mathrm{~L} / \mathrm{min}$ and gas temperature at $365{ }^{\circ} \mathrm{C}$ with a constant pressure of $0.6 \mathrm{psi}$. The current of the corona discharge needle was $1000 \mathrm{nA}$ and capillary voltage $1000 \mathrm{~V}$. The fragmentor voltage was $150 \mathrm{~V}$ and skimmer voltage $65 \mathrm{~V}$.

QTOFMS data were recorded over the $m / z$ range of $50-400$ with an acquisition rate of 5 spectra/s. MS/MS spectra of the NPS were collected in the targeted MS/MS mode. Initial external mass calibration was carried out using the electrospray ionization (ESI) source with an ESI tuning mix (Agilent). Compounds were processed and handled with MassHunter Qualitative Analysis B.07.00. 
NCD analysis Caffeine was used for external calibration. Caffeine was weighed and dissolved in methanol to obtain a stock solution of $1 \mathrm{mg} / \mathrm{mL}$. Subsequently, this solution was diluted in butyl acetate to obtain working solutions for six calibration points ranging from 0.15 to $4 \mu \mathrm{g} / \mathrm{mL}$, equaling from 11.1 to $295.6 \mathrm{pg} / N$, respectively, when a $1.5-\mu \mathrm{L}$ injection volume was applied. External calibration was performed at the beginning of each data acquisition sequence with caffeine. The equimolarity of nitrogen detection was investigated by comparison of the concentration obtained from the external calibration to the concentration of each NPS reference standard at five different concentration levels $(0.17-1.7 \mathrm{mg} / \mathrm{L})$ using five replicates. The area of the internal standard was used to compensate for variation in all calibrations and measurements.

Pyrolysis of the analytes in the NCD was carried out at $900{ }^{\circ} \mathrm{C}$ under a hydrogen flow rate of $4 \mathrm{~mL} / \mathrm{min}$ and an oxygen flow rate of $9.4 \mathrm{~mL} / \mathrm{min}$. Data from the NCD was collected at $50 \mathrm{~Hz}$ over the entire course of the analysis. OpenLab CDS Chemstation GC driver A.02.05.021 was used to control the GC-NCD.

\section{Results and discussion}

Coupling of GC-APCI-QTOFMS with NCD In the present analytical platform, the GC flow was divided in appropriate proportions, using a flow splitter and uncoated deactivated fused-silica post-columns of different lengths, between NCD and APCI-QTOFMS to obtain a comparable performance level for the five NPS on both detectors. APCI-QTOFMS allowed accurate mass-based identification using protonated molecules $[\mathrm{M}+\mathrm{H}]^{+}$and their characteristic product ions. The NCD was used for single-calibrant quantification with the external standard caffeine, utilizing the detector's sensitive equimolar response to nitrogen. Separate software from the same manufacturer was applied to the qualitative and quantitative sections of the total analysis.

The NPS chosen for this study represented typical psychostimulant drugs encountered on the illicit market. Bupropion, 2-DPMP, mephedrone, and methylone are aliphatic secondary amines and naphyrone an aliphatic tertiary amine. The present approach allowed simultaneous qualitative and quantitative analysis of these compounds without derivatization at relevant concentration levels in blood.

Identification by GC-APCI-QTOFMS Table 1 shows the GC-APCI-QTOFMS data (precursor ions, product ions, and retention times) for the five NPS spiked post-extraction in sheep blood. These data are concordant with the published ESI mass spectral data for each drug, mephedrone [8], bupropion [8], methylone [9], 2-DPMP [10], and naphyrone [11]. The soft APCI ionization allowed the choice of abundant protonated molecules $[\mathrm{M}+\mathrm{H}]^{+}$as precursor ions, in contrast to the extensive fragmentation often encountered in electron ionization (EI) spectra. All compounds showed abundant $[\mathrm{M}+\mathrm{H}]^{+}$ions and negligible radical cations $\left(\mathrm{M}^{+}\right)$; thus,
Table 1 GC-APCI-QTOFMS data (precursor ions, product ions, and retention times) for new psychoactive substances spiked post-extraction at $1.7 \mathrm{mg} / \mathrm{L}$ in sheep blood

\begin{tabular}{llllll}
\hline Compound & $\begin{array}{l}\text { Molecular } \\
\text { formula }\end{array}$ & $\begin{array}{l}\text { Retention } \\
\text { time } \\
(\mathrm{min})\end{array}$ & $\begin{array}{l}\text { Exact } \\
\text { monoisotopic } \\
\text { mass } \\
{[\mathrm{M}+\mathrm{H}]^{+}(\mathrm{Da})}\end{array}$ & $\begin{array}{l}\text { Measured } \\
\text { monoisotopic } \\
\text { mass }^{\mathrm{a}}[\mathrm{M}+\mathrm{H}]^{+} \\
(\mathrm{Da})\end{array}$ & $\begin{array}{l}\text { Mass difference } \\
\text { (exact- } \\
\text { measured) } \\
(\mathrm{mDa})\end{array}$ \\
\hline Mephedrone & $\mathrm{C} 11 \mathrm{H} 15 \mathrm{NO}$ & 5.2 & 178.1226 & 178.1225 & 0.1 \\
product 1 & $\mathrm{C} 11 \mathrm{H} 14 \mathrm{~N}$ & & 160.1121 & 160.1110 & 1.1 \\
product 2 & $\mathrm{C} 10 \mathrm{H} 11 \mathrm{~N}$ & & 145.0886 & 145.0877 & 0.9 \\
Bupropion & $\mathrm{C} 13 \mathrm{H} 18 \mathrm{ClNO}$ & 5.8 & 240.1150 & 240.1144 & 0.6 \\
product 1 & $\mathrm{C} 9 \mathrm{H} 11 \mathrm{ClNO}$ & & 184.0524 & 184.0509 & 1.5 \\
product 2 & $\mathrm{C} 9 \mathrm{H} 9 \mathrm{ClN}$ & & 166.0418 & 166.0403 & 1.5 \\
Methylone & $\mathrm{C} 11 \mathrm{H} 13 \mathrm{NO} 3$ & 6.2 & 208.0968 & 208.0969 & -0.1 \\
product 1 & $\mathrm{C} 11 \mathrm{H} 12 \mathrm{NO} 2$ & & 190.0863 & 190.0862 & 0.1 \\
product 2 & $\mathrm{C} 10 \mathrm{H} 10 \mathrm{NO}$ & & 160.0757 & 160.0757 & 0.0 \\
2-DPMP & $\mathrm{C} 18 \mathrm{H} 21 \mathrm{~N}$ & 7.3 & 252.1747 & 252.1743 & 0.4 \\
product 1 & $\mathrm{C} 15 \mathrm{H} 13$ & & 193.1012 & 193.0996 & 0.6 \\
product 2 & $\mathrm{C} 7 \mathrm{H} 7$ & & 91.0542 & 91.0536 & -0.7 \\
Naphyrone & $\mathrm{C} 19 \mathrm{H} 23 \mathrm{NO}$ & 8.2 & 282.1852 & 282.1859 & -0.4 \\
product 1 & $\mathrm{C} 11 \mathrm{H} 9$ & & 141.0699 & 141.0703 & -0.3 \\
product 2 & $\mathrm{C} 8 \mathrm{H} 16 \mathrm{~N}$ & & 126.1277 & 126.1280 & \\
\hline
\end{tabular}

${ }^{\mathrm{a}}$ Measured mass is mean of three separate measurements on different days. Precursor ions $[\mathrm{M}+\mathrm{H}]^{+}$are from MS experiments and product ions from MS/MS experiments applying the following collision energies: mephedrone $20 \mathrm{eV}$, bupropion $10 \mathrm{eV}$, methylone $10 \mathrm{eV}$, 2-DPMP $20 \mathrm{eV}$, and naphyrone $40 \mathrm{eV}$ 
Table 2 Equimolarity of GCNCD in five separate experiments for new psychoactive substances spiked post-extraction at different concentration levels in sheep blood

\begin{tabular}{|c|c|c|c|c|c|c|c|c|c|}
\hline \multirow[t]{2}{*}{ Drug } & \multirow{2}{*}{$\begin{array}{l}\text { Amount of nitrogen } \\
\text { per injection (pg) }\end{array}$} & \multirow{2}{*}{$\begin{array}{l}\mathrm{C} \\
(\mathrm{mg} / \\
\mathrm{L})\end{array}$} & \multicolumn{7}{|c|}{ Equimolarity (\%) } \\
\hline & & & $\begin{array}{l}\text { Exp. } \\
1\end{array}$ & $\begin{array}{l}\text { Exp. } \\
2\end{array}$ & $\begin{array}{l}\text { Exp. } \\
3\end{array}$ & $\begin{array}{l}\text { Exp. } \\
4\end{array}$ & $\begin{array}{l}\text { Exp. } \\
5\end{array}$ & Mean & $\mathrm{CV} \%$ \\
\hline \multirow[t]{5}{*}{ Mephedrone } & 20.2 & 0.17 & 88.0 & 110.5 & 91.2 & 107.7 & 84.0 & 96.3 & 12.5 \\
\hline & 40.3 & 0.34 & 81.8 & 100.8 & 82.5 & 87.7 & 95.6 & 89.7 & 9.3 \\
\hline & 60.5 & 0.51 & 84.9 & 91.7 & 92.3 & 81.9 & 85.3 & 87.2 & 5.2 \\
\hline & 101 & 0.85 & 83.3 & 97.4 & 88.7 & 77.6 & 86.4 & 86.7 & 8.4 \\
\hline & 202 & 1.7 & 81.9 & 100.7 & 84.8 & 92.6 & 82.5 & 88.5 & 9.1 \\
\hline \multirow[t]{5}{*}{ Bupropion } & 17.2 & 0.17 & 105.9 & 95.1 & 102.8 & 104.0 & 102.2 & 102.0 & 4.0 \\
\hline & 34.5 & 0.34 & 98.4 & 95.4 & 100.9 & 97.1 & 98.6 & 98.1 & 2.1 \\
\hline & 51.7 & 0.51 & 106.6 & 109.8 & 98.3 & 94.0 & 100.0 & 101.7 & 6.3 \\
\hline & 86.2 & 0.85 & 102.2 & 110.3 & 96.5 & 92.4 & 98.2 & 99.9 & 6.8 \\
\hline & 172 & 1.7 & 95.1 & 117.4 & 96.7 & 103.3 & 103.7 & 103.2 & 8.5 \\
\hline \multirow[t]{5}{*}{ Methylone } & 14.9 & 0.17 & 91.5 & 93.9 & 106.6 & 107.9 & 88.4 & 97.7 & 9.2 \\
\hline & 29.8 & 0.34 & 85.0 & 82.5 & 105.6 & 111.9 & 95.8 & 98.0 & 13.2 \\
\hline & 44.7 & 0.51 & 92.1 & 90.8 & 107.9 & 107.4 & 106.4 & 100.9 & 8.6 \\
\hline & 74.5 & 0.85 & 88.3 & 95.3 & 111.2 & 107.0 & 113.1 & 103.0 & 10.4 \\
\hline & 149 & 1.7 & 89.5 & 94.5 & 108.3 & 112.1 & 118.2 & 104.5 & 11.6 \\
\hline \multirow[t]{5}{*}{ 2-DPMP } & 14.2 & 0.17 & 111.0 & 113.9 & 107.8 & 98.2 & 95.3 & 105.2 & 7.7 \\
\hline & 28.4 & 0.34 & 96.7 & 100.0 & 122.5 & 130.1 & 129.2 & 115.7 & 14.0 \\
\hline & 42.6 & 0.51 & 107.5 & 110.1 & 118.9 & 123.2 & 121.0 & 116.1 & 6.0 \\
\hline & 71.1 & 0.85 & 109.9 & 98.7 & 114.6 & 112.2 & 117.6 & 110.6 & 6.5 \\
\hline & 142 & 1.7 & 112.4 & 108.9 & 112.5 & 127.9 & 123.0 & 116.9 & 6.9 \\
\hline \multirow[t]{5}{*}{ Naphyrone } & 12.7 & 0.17 & 85.4 & 111.6 & 96.5 & 85.5 & 80.0 & 91.8 & 13.7 \\
\hline & 25.4 & 0.34 & 86.6 & 112.0 & 87.3 & 94.9 & 86.8 & 93.5 & 11.7 \\
\hline & 38.1 & 0.51 & 86.6 & 106.4 & 84.3 & 82.8 & 76.7 & 87.4 & 12.9 \\
\hline & 63.5 & 0.85 & 86.1 & 91.5 & 78.0 & 88.7 & 82.3 & 85.3 & 6.2 \\
\hline & 127 & 1.7 & 86.2 & 95.0 & 77.3 & 86.4 & 89.6 & 86.9 & 7.4 \\
\hline
\end{tabular}

Measured on separated days using respective external calibration based on caffeine further optimization of ionization parameters was not needed to increase the $[\mathrm{M}+\mathrm{H}]^{+} / \mathrm{M}^{+}$. abundance ratio.

During the last decade, many researchers have recognized the merits of the GC-APCI interface in terms of lower quantification limits, broader linear ranges, and improved repeatability especially for late-eluting compounds compared to EI [12]. A concept involving a GC-APCI-QTOFMS webbased spectral library has been presented, including spectra of 150 compounds from the most common chemical families [13]. However, our preliminary results suggest that the mass
Fig. 1 GC-NCD chromatogram of five NPS spiked postextraction at $1.7 \mathrm{mg} / \mathrm{L}$ in sheep blood. Compound identification: 1, mephedrone; 2, bupropion; 3, methylone; 4, 2-DPMP; 5 , naphyrone; 6 , dibenzepine-D3 (internal standard)

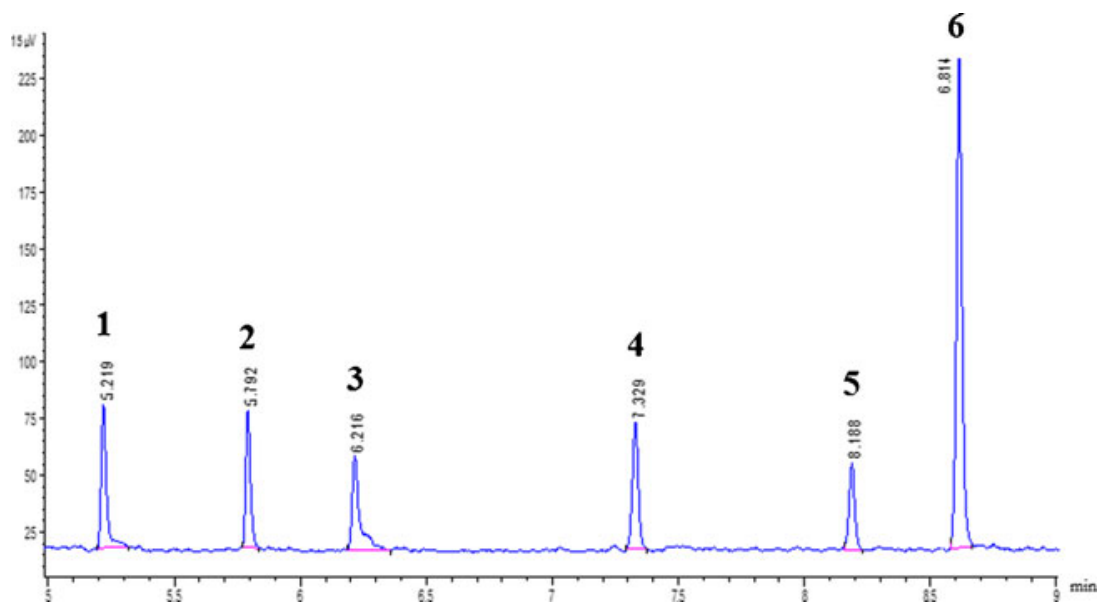


spectra of NPS obtained by GC-APCI-QTOFMS bear good resemblance with those recorded by LC-ESI-QTOFMS, which may enable library search against the comprehensive ESI libraries readily available.

Quantification by NCD Table 2 shows the equimolarity of nitrogen chemiluminescence detection by five separate GCNCD experiments for the NPS spiked post-extraction at five concentration levels in sheep blood. The equimolarity was on average $98.7 \%$, and the range of all individual equimolarity determinations was $76.7-130.1 \%$. The coefficient of variation for the five replicate measurements ranged from 2.1 to $14 \%$. These results indicate that GC-NCD can provide a general means for accurate quantification of NPS without authentic reference standards at a performance level comparative to ordinary drug analysis. Figure 1 illustrates a GC-NCD chromatogram of the five NPS spiked post-extraction at $1.7 \mathrm{mg} /$ $\mathrm{L}$ in sheep blood.

According to the manufacturer's specifications, the sensitivity of the $255 \mathrm{NCD}$ is $<3 \mathrm{pg}$ nitrogen/s (signal to noise $3: 1$ ) and linearity $>10^{4}$. The aim of the present study was not to challenge these values, and consequently the performance was only tested using a limited concentration range in blood. The lowest concentration tested $(0.17 \mathrm{mg} / \mathrm{L}$ in blood $)$ was approximately the method's lower limit of quantification (LLOQ) using the current indicative sample work-up procedure. The concentrations reported in the literature for stimulant-type NPS range widely $[14,15]$, the highest concentrations in blood being up to $7 \mathrm{mg} / \mathrm{L}$ [14]. The present LLOQ seems to be quite appropriate for investigating stimulant-related deaths [15]. In living, the target concentration range would be approximately from 0.02 to $2 \mathrm{mg} / \mathrm{L}$ in blood, requiring an almost 10-fold improvement for the present LLOQ. In future research, we will elaborate the method in terms of sensitivity by way of sample preparation, derivatization, and optimization of the GC-NCD analysis, including sample introduction. For sample preparation, salting-out-assisted liquid-liquid extraction is a viable option, covering a wide range of analyte polarity with steadily high recoveries [16].

GC-NCD has been found to be a feasible instrument especially in petroleum refinery for the speciation and quantification of families of nitrogen compounds $[17,18]$. In a comparison study, the Sievers type of NCD detector that we used in the present study performed better than the Antek-type detector in terms of peak width and shape [17]. Interestingly, the $\mathrm{N}$ equimolar response of GC-NCD has been recognized only in few studies, such as in the determination of 14 organic nitrogen compounds in urban aerosol samples [19] and six volatile nitrosamines in grilled sheep and vegetables [20]. In these two studies, the accuracy of $\mathrm{N}$-equimolar NCD quantification was good, the bias remaining within 12 and $7.3 \%$, respectively. However, no study prior to ours has used the GC-NCD-APCI-
QTOFMS platform for simultaneous identification and quantification.

In an interesting study, Dahal et al. [21] examined if the calibration with a parent drug can be used to quantify its metabolites by using conventional flow ESI and low-flow captive spray ionization (CSI) LC-MS techniques. The signals of the parent drugs as compared with those of the metabolites were significantly different (up to 4-fold) for metabolite/parent pairs for $O$-demethylation, $\mathrm{N}$-demethylation, aromatic hydroxylation, and benzylic hydroxylation, but were slightly less for the CSI method. They also demonstrated that the signal of the compound is an intrinsic property of the compound and not related to any given metabolic pathway [21]. These findings emphasize the need of a bioanalytical detection technique with universal or calculable response, such technique being the GC-NCD currently reported here for the nitrogen containing NPS.

\section{Conclusions}

The analytical platform presented in this study enabled a straightforward resolution to the common challenge of analyzing NPS in cases where appropriate reference standards are not readily available. We anticipate that this approach possesses great potential not only in analytical toxicology but also in other fields of analysis. Yet should the results obtained without actual reference standards be based on careful validation to be eligible in a legal context. At this point, our results were obtained by analyzing blood samples spiked postextraction to avoid emphasizing recovery issues. Our future research will focus on the library search options, control of sample preparation to compensate for recovery, as well as on the development of derivatization methods to further improve sensitivity.

Compliance with ethical standards The experiments were conducted in accordance with animal ethical care.

Conflict of interest The authors declare that they have no conflict of interest.

\section{References}

1. Ojanperä I, Kolmonen M, Pelander A. Current use of highresolution mass spectrometry in drug screening relevant to clinical and forensic toxicology and doping control. Anal Bioanal Chem. 2012;403:1203-20.

2. Arnhard K, Gottschall A, Pitterl F, Oberacher H. Applying 'Sequential windowed acquisition of all theoretical fragment Ion mass spectra' (SWATH) for systematic toxicological analysis with 
liquid chromatography-high-resolution tandem mass spectrometry. Anal Bioanal Chem. 2015;407:405-14.

3. Nedderman AN, Dear GJ, North S, Obach RS, Higton D. From definition to implementation: a cross-industry perspective of past, current and future MIST strategies. Xenobiotica. 2011;41:605-22.

4. Laks S, Pelander A, Vuori E, Ali-Tolppa E, Sippola E, Ojanperä I. Analysis of street drugs in seized material without primary reference standards. Anal Chem. 2004;76:7375-9.

5. Rasanen I, Kyber M, Szilvay I, Rintatalo J, Ojanperä I. Straightforward single-calibrant quantification of seized designer drugs by liquid chromatography-chemiluminescence nitrogen detection. Forensic Sci Int. 2014;237:119-25.

6. Ojanperä S, Tuominen S, Ojanperä I. Single-calibrant quantification of drugs in plasma and whole blood by liquid chromatographychemiluminescence nitrogen detection. J Chromatogr B Analyt Technol Biomed Life Sci. 2007;856:239-44.

7. Ojanperä S, Rasanen I, Sistonen J, Pelander A, Vuori E, Ojanperä I. Quantification of drugs in plasma without primary reference standards by liquid chromatography-chemiluminescence nitrogen detection: application to tramadol metabolite ratios. Ther Drug Monit. 2007;29:423-8.

8. Horai H, Arita M, Kanaya S, Nihei Y, Ikeda T, Suwa K, et al. MassBank: a public repository for sharing mass spectral data for life sciences. J Mass Spectrom. 2010;45:703-14.

9. Strano Rossi S, Odoardi S, Gregori A, Peluso G, Ripani L, Ortar G, et al. An analytical approach to the forensic identification of different classes of new psychoactive substances (NPSs) in seized materials. Rapid Commun Mass Spectrom. 2014;28:1904-16.

10. Tyrkkö E, Pelander A, Ketola RA, Ojanperä I. In silico and in vitro metabolism studies support identification of designer drugs in human urine by liquid chromatography/quadrupole-time-of-flight mass spectrometry. Anal Bioanal Chem. 2013;405:6697-709.

11. Meyer MR, Prosser D, Maurer HH. Studies on the metabolism and detectability of the designer drug $\beta$-naphyrone in rat urine using GC-MS and LC-HR-MS/MS. Drug Test Anal. 2013;5:259-65.

12. Wachsmuth CJ, Hahn TA, Oefner PJ, Dettmer K. Enhanced metabolite profiling using a redesigned atmospheric pressure chemical ionization source for gas chromatography coupled to highresolution time-of-flight mass spectrometry. Anal Bioanal Chem. 2015;407:6669-80.

13. Pacchiarotta T, Derks RJ, Hurtado-Fernandez E, van Bezooijen P, Henneman A, Schiewek R, et al. Online spectral library for GCatmospheric pressure chemical ionization-ToF MS. Bioanalysis. 2013;5:1515-25.

14. Adamowicz P, Gieroń J, Gil D, Lechowicz W, Skulska A, Tokarczyk B. The prevalence of new psychoactive substances in biological material - a three-year review of casework in Poland. Drug Test Anal. 2016;8:64-71.

15. Elliott S, Evans J. A 3-year review of new psychoactive substances in casework. Forensic Sci Int. 2014;243:55-60.

16. Hajkova K, Jurasek B, Sykora D, Palenicek T, Miksatkova P, Kuchar M. Salting-out-assisted liquid-liquid extraction as a suitable approach for determination of methoxetamine in large sets of tissue samples. Anal Bioanal Chem. 2016;408:1171-81.

17. Adam F, Bertoncini F, Brodusch N, Durand E, Thiébaut D, Espinat $\mathrm{D}$, et al. New benchmark for basic and neutral nitrogen compounds speciation in middle distillates using comprehensive twodimensional gas chromatography. J Chromatogr A. 2007;1148: $55-64$.

18. Dijkmans T, Djokic M, Van Geem K, Marin G. Comprehensive compositional analysis of sulfur and nitrogen containing compounds in shale oil using GC x GC - FID/SCD/NCD/TOF-MS. Fuel. 2015;140:398-406.

19. Özel MZ, Hamilton JF, Lewis AC. New sensitive and quantitative analysis method for organic nitrogen compounds in urban aerosol samples. Environ Sci Technol. 2011;45:1497-505.

20. Kocak D, Özel MZ, Gogus F, Hamilton JF, Lewis AC. Determination of volatile nitrosamines in grilled sheep and vegetables using comprehensive gas chromatography-nitrogen chemiluminescence detection. Food Chem. 2012;135:2215-20.

21. Dahal UP, Jones JP, Davis JA, Rock DA. Small molecule quantification by liquid chromatography-mass spectrometry for metabolites of drugs and drug candidates. Drug Metab Dispos. 2011;39:2355-60. 